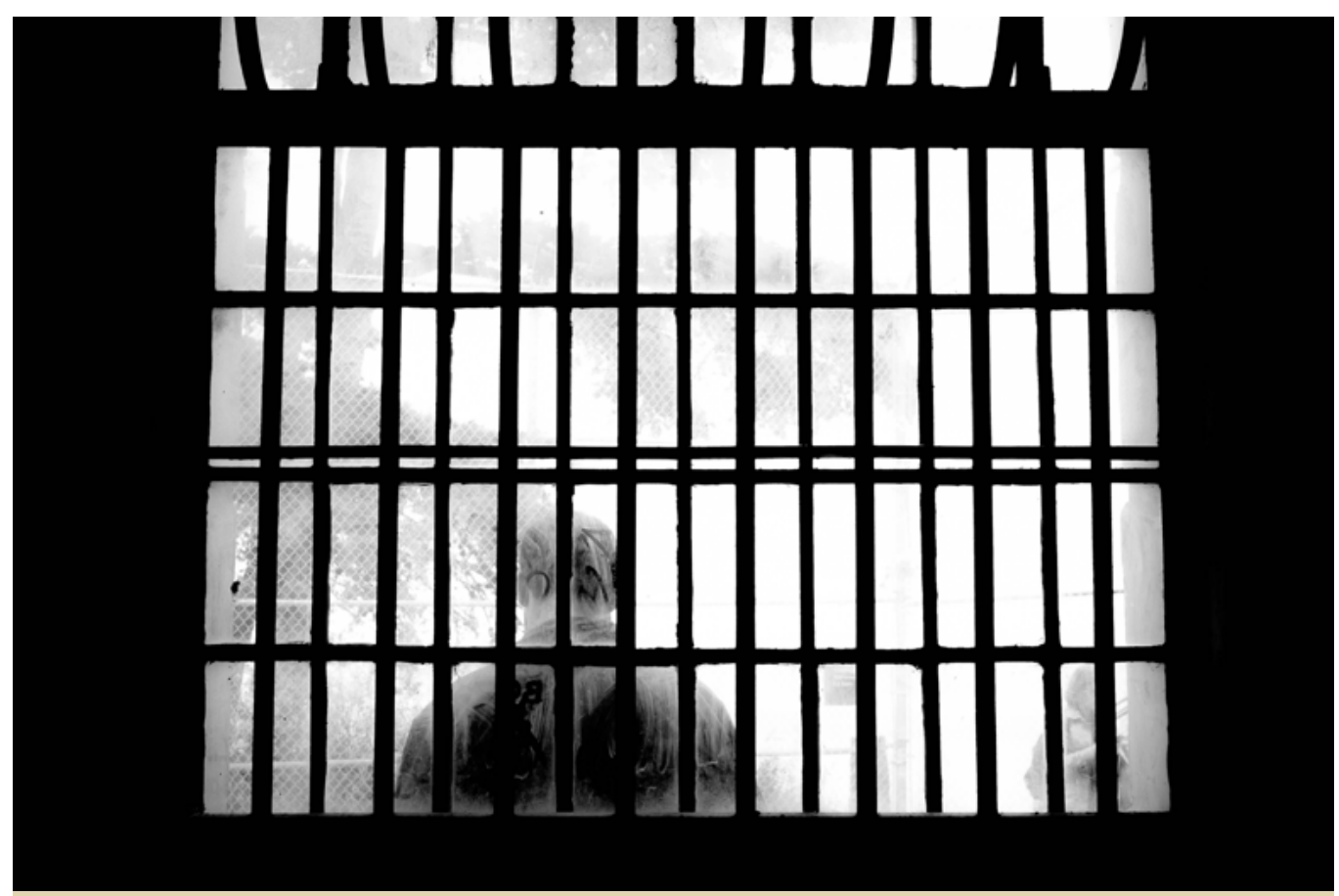

\section{Migrants, Mass Arrest, and Resistance in Contemporary China}

\section{Ma Tian}

In today's China, migrant workers are commonly perceived as criminals. This essay examines how this bias is reflected in mechanisms of crime control, as well as in the judicial and correctional systems. It also looks into the strategies adopted by migrants to cope with this kind of discrimination by the law enforcement bodies.
In Chinese society today, migrant workers are commonly perceived as criminals. This can be clearly seen in various mechanisms of the crime control regime, with the migrant population being stopped and searched more frequently than local populations, and experiencing a disproportionately high rate of police arrests and pre-trial incarceration. Migrants are also more likely to receive longer sentences, to be denied parole and probation, and to receive discriminatory treatment in the correctional system.

To address existing biases in the arrest rate of migrant suspects, between 2011 and 2015 more than twenty first-tier cities in China initiated legal reforms. Still, when I was doing fieldwork in major cities in the Yangtze River Delta back in 2015, prosecutors explicitly acknowledged that in their daily work they simply followed the principle of 'arresting all' (yilü shiyong jiyaxing qiangzhi cuoshi) when it came to migrant 
suspects. In their opinion, the reforms were 'totally infeasible, contradictory, and utterly ridiculous.' Similarly, policemen I interviewed in Ningbo during that period affirmed that they had never even heard of the new legislation. Apparently, the ambitious reform programme outlined in official legal documents had essentially come to naught. This failed reform highlights how hukou status still plays a fundamental role in determining how the police and judicial bodies in China deal with different types of suspects.

\section{Hukou Disparity in Arrest Decisions}

It is a fact that prosecutors in China are more prone to issue or approve an arrest warrant for migrant suspects. For instance, according to internal documents of the local Procuratorate, in Ningbo in 2010, the arrest rate for the migrant population was 368 arrests per 100,000 people-7.36 times higher than the rate for local residents. In light of this, the police find it easier to target migrants, as their arrest is more likely to be officially sanctioned. This dynamic of mutual reinforcement not only engenders discrimination against migrants, but also leads to a disproportionate arrest rate within this social group-in fact, we can talk about this phenomenon as being a form of 'mass arrest'.

Far from being simply the result of the personal preferences of individual police officers, this bias has been systematised, rationalised, and legalised. Article 5.6 of the Quality Standards for the Examination of Arrest Requests by People's Procuraturates provides specific procedural instructions to legal professionals, mandating that if the criminal suspect has no fixed residence, or commits crimes from place to place or in different places, and does not possess the conditions for bail or residential confinement', he shall be arrested (Supreme People's Procuratorate 2010). One of my interviewees, a prosecutor from a district procuraturate in Shanghai, confirmed that it was this link between the absence of a 'fixed residence' to a 'non-local hukou' that resulted in the establishment of standardised arrest guidelines in China. In this way, the creation of a causal link between migration and criminality has resulted in a major bias in the approval rate of arrest warrants targeting migrants.

Besides being legalised and institutionalised, this logic is also enshrined in routine everyday practice. Migrants are discursively equated with crime, and thus with instability and danger. Given the risk that migrants could 'run away', positive arrest decisions targeting this kind of suspect are justified as essential to ensure the defendant's return for subsequent proceedings. However, this apparent necessity is, in actuality, based on an illogical assumption formalised through the law.

\section{Coping with Police Discrimination}

My research shows that the benefits of the judicial reforms of the early 2010s have not trickled down to migrants. When suspected of a crime, they still found themselves stuck in the Kafkaesque position of being subject to relentless interrogations and arrests due to their hukou status rather than actual misbehaviour. In such recurring circumstances, migrants have no choice but to cope with the police strategically.

Article 10 of the Regulations on Detention Centres of the People's Republic of China (State Council 1990) stipulates that criminals have to go through a health check prior to detention, and lists three medical conditions under which they cannot be detained: a) Mental illness or acute infectious disease; b) Other serious illnesses that may be life- 


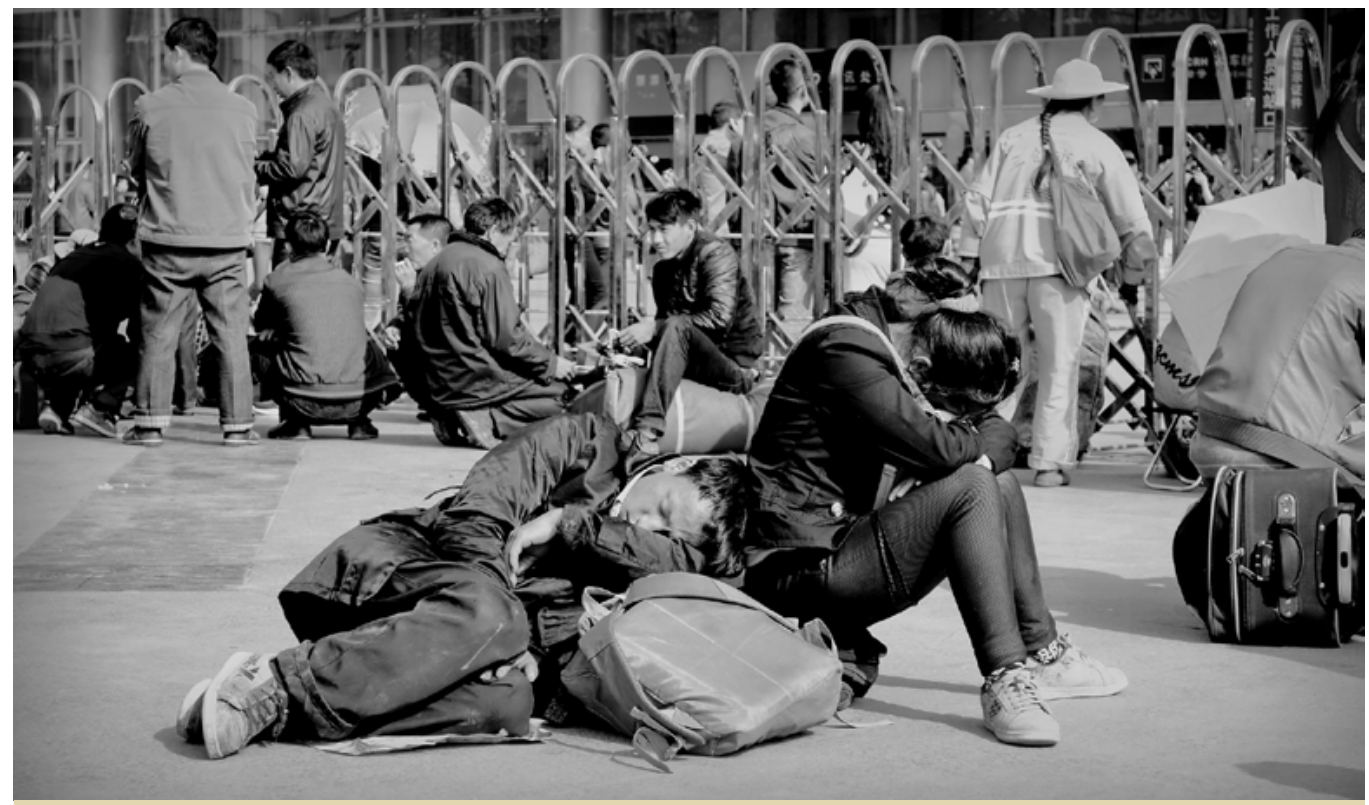

Chengdu, North Train Station. Photo: Phoootoooos, Flickr.

threatening while in custody or for which they can not take care of themselves (this does not apply to those who are extremely dangerous to society); and c) Pregnancy or breastfeeding of children less than one year old. Taking advantage of these legal guarantees, many migrants attempt to place themselves into these scenarios in order to evade arrest and detention. The most common coping strategies include putting oneself in a life-threatening situation for male migrants ( $\mathrm{Li}$ 2016), and pregnancy or simply cuddling a baby for female migrants.

In my interviews, the police continually complained about how 'crafty' (jiaohua) migrant suspects are nowadays. They vividly described their encounters with migrants who, in order to avoid arrest, swallowed blades, coins, keys, zips, screws, nails, nail clippers, and even saws. These occurrences were regarded as complicated and difficult to resolve. A policeman told me a story about a migrant 'thief' who used to carry nails with him at all times. 'After we caught him, he swallowed the nails instantly. The detention centre (kanshousuo) carries out $\mathrm{X}$-ray checks for all incoming detainees before taking them into custody. If they see things like these in their stomach, they will not accept them.' Under these circumstances, he continued, 'We had to let him go... After being released, he continued to steal. Then he went through prosecution and trial. Although the court sentenced him to prison, the jail still did not want to take him. What can we do? He continues to steal, but our hands are tied. There is nothing we can do.'

This process of 'othering' was repeated in encounters between the police and suspects, enhancing the discursive framing of migrants as having violent and irrational tendencies. In some cases, this discourse overlaps with other narratives and concerns related to specific ethnic minorities. For instance, Muslims from Xinjiang are often marked out for their 'savageness and aggression'. As one police officer told me: 'We caught several people from Xinjiang. Once he put some blades into his mouth, and 
then chewed the blades. Lots of bloods came out of his mouth, I was frightened to death, we just let him go.'

Female migrants often use motherhood to avoid arrest. In his master's dissertation, Li Weiming (2013) found that in Shanghai numerous organised crime groups from Hunan province recruit women who are pregnant or have a small baby. A woman told Li how she came to join the group: 'My townsfolk told me that nowadays pregnant women are all doing this. They said: "You are pregnant. What a pity if you don't do this!" Sometimes, women have abortions after months of pregnancy, and then get pregnant again just to stay out of jail.

\section{Blurred Morality and Resistance}

This essay certainly does not intend to glorify migrant coping strategies, or suggest that migrant suspects are activists leading a non-violent life in a context of apartheid. However, their actions cannot only be understood as a devious way to avoid criminal charges. From feigning illness to skipping a class, to soldiers deliberately harming themselves in order to escape the war; from espionage agents taking a cyanide pill to avoid torture, to people grabbing a baby at the very last minute to gain a seat on a lifeboat, it is never easy to distinguish between courageous acts and irresponsible cowardice. These examples all demonstrate that resistance is a complex set of actions that go against an established order. In other words, resistance-or the act of saying nois, by its very nature, contentious.

Facing the real possibility of arrest and pre-trial incarceration, migrant suspects look for alternatives for self-redemption. There are two layers of 'resistance' in the coping strategies outlined in this essay. The first layer lies within the offender's noncompliant behaviours during his or her interactions with the police. In this case, rather than being verbally or physically aggressive, the resistance is actually nonviolent. It is a tangible, subtle, even silent act. The second layer resonates with the idea of resistance or rebellion in cultural criminology. As Jock Young pointed out in The Criminological Imagination, 'resistance is always there' (2007, 77). Self-harm and pregnancy should also be seen as 'forms of resistance' against discriminative policing. At a disadvantage in the criminal justice system, migrant suspects change their own bodies to resist the asymmetrical power relationships between themselves and those administering 'justice'. For these subversive migrants, nails in the stomach and foetuses in the womb become a type of protection from discriminatory incarceration. 
This text is taken from Gilded Age: A Year of Chinese Labour, Civil Society, and Rights, Made in China Yearbook 2017, edited by Ivan Franceschini and Nicholas Loubere, published 2018 by ANU Press, The Australian National University, Canberra, Australia.

doi.org/10.22459/MIC.04.2018.10 